\title{
Equipment
}

\section{Oxygen flow through nasal cannulae}

Cynthia L. Henderson MD FRCPC, $\uparrow$

H. David Rosen MD, $†$ K. Louise Arney RRT*

Purpose: Since many operating theatres do not have distinct oxygen flowmeters, flow rates of oxygen were measured via nasal prongs at several settings and attachments to three anaesthetic machines.

Methods: Oxygen flow rates were measured using a Timeter $R$ $T$-200 Calibration Analyzer at three, five and eight $L \cdot \mathrm{min}^{-1}$ via nasal prongs attached to a distinct flowmeter, the common gas outlet (CGO) and the Y-piece of a circle system with the adjustable pressure release ( $A P L$ ) valve closed, open and partially open at circuit pressures of 10 and $20 \mathrm{~cm} \mathrm{H}_{2} \mathrm{O}$.

Results: The most accurate delivery of oxygen was from a distinct flowmeter and the $\mathrm{CGO}$ (mean difference $0.2 \pm 0.2$ and $0.4 \pm 0.4$ respectively). Differences between the flowmeter and CGO were not significant $(P=0.1)$. Accuracy of flows via the $Y$-piece were worse than via the flowmeter and CGO $(P<$ $0.0001)$. Flows via the Y-piece were less than those dialed, especially at high rates. With a partially open APL valve, flow depended upon pressure in the anaesthetic circuit, not upon the flow set. With the APL valve completely open, no flow occurred.

Conclusions: To deliver supplemental oxygen in the operating theatre when there are no distinct flowmeters, nasal prongs should be attached to the CGO of the anaesthetic machine or a flowmeter on a portable E-tank oxygen cylinder. Connecting nasal prongs to the $Y$-piece of a circle system should be avoided since oxygen delivery is less than dialed, especially when the APL valve is open.

Objectif: Comme plusieurs salle d'opérations ne sont pas équipées de débitmètres indépendants pour l'oxygène, les

\section{Key words}

OXYGEN: delivery systems, nasal prongs.

From the Departments Of Anaesthesia† and Respiratory Therapy*, St. Paul's Hospital, University of British Columbia, 1081 Burrard Street, Vancouver, B.C. Canada V6Z 1 Y6.

Address correspondence to: Dr. Cynthia Henderson,

Department of Anaesthesia, Vancouver Hospital 12th and Oak Site, 910 West 10th Avenue, Vancouver, BC V5Z 4E3.

Accepted for publication 21 February, 1996. débits d'oxygènes provenant de lunettes nasales (canules nasales à deux crocs) ont été mesurés sous différents réglages et montages sur trois appareils d'anesthésie.

Méthodes: Les débits d'oxygène ont été mesurés grâce à un dispositif Timeter RT-200 Calibration Analyzer à trois, cinq et huit $L \cdot \mathrm{min}^{-1}$ sur une lunetre nasale reliée à un débitmètre, l'orifice de sortie des gaz, et la pièce en Y d'un circuit avec absorption avec une valve de surpression fermée, ouverte et partiellement ouverte pour des pressions de 10 et $20 \mathrm{CmH}_{2} \mathrm{O}$.

Résultats: Ce sont le débilmètre indépendant et l'orifice des gaz frais qui ont livré l'oxygène avec la plus grande précision (différence moyenne respective de $0,2 \pm 0,2$ et $0,4 \pm 0,4$ ). La différence entre le débitmètre indépendant et l'orifice de sortie des gaz frais n'était pas significative $(P=0,1)$. La précision du débit par le raccord en $Y$ était inférieure à celle du débitmètre et de l'orifice de sortie des gaz frais $(P<0.0001)$. Les débits, surtout les débits élevés, mesurés au raccord en $Y$ étaient inférieurs aux réglages. Avec une valve de surpression partiellement ouverte, le débit a été inexistant.

Conclusions: Pour délivrer l'oygène supplémentaire dans une salle d'opération non équipée de débitmètre indépendant, la lunette nasale devrait être reliée à l'orifice de sortie des gaz frais de l'appareil d'anesthésie ou à un débirmètre fixé sur un cylindre d'oxygène. Comme le débit d'oxygène est inférieur au réglage choisi, surtout lorsque le débit est élevé, le branchement d'une lunette nasale sur le raccord en $Y$ d'un circuit avec absorption devrait être évité.

At our institution, most operating theatres do not have distinct oxygen flowmeters for delivering supplemental oxygen to patients. An informal survey of our colleagues revealed many different methods for attaching nasal prongs to the anaesthetic machine to provide supplemental oxygen during conscious sedation.

Previous studies of nasal prongs have discussed the fraction of inspired oxygen $\left(\mathrm{FIO}_{2}\right)$ delivered by nasal prongs,' the range of $\mathrm{FIO}_{2}$ produced, ${ }^{2}$ and the effect on $\mathrm{FIO}_{2}$ of mouth breathing, ${ }^{3.4}$ oxygen flow setting, and peak inspiratory flow; ${ }^{5}$ but in all the studies, the nasal prongs were attached directly to a wall flowmeter. There 
have been no reports in the literature measuring oxygen delivery via nasal prongs attached to the anaesthetic machine. The goal of our study was to quantify the flow rates of oxygen at several settings and various configurations of attachment of nasal prongs to the anaesthetic machine.

\section{Methods}

A standard set of nasal prongs was fitted with an adapter that allowed flow through the prongs to be diverted to a flow measuring device (Timeter RT-200 Calibration Analyzer). The apparatus consisted of metal small bore tubing adapters which fit over the prongs, and a short length of semi-rigid Tygon tubing (Figure 1). The same apparatus, including nasal prongs, disposable circle system tubing and rebreathing bag, was used for all measurements and the analyzer was re-calibrated between each reading. The nasal prongs were connected to three locations: (1) a distinct oxygen flowmeter (2) the common gas outlet (CGO) and (3) the Y-piece of a circle system. A $15-\mathrm{mm}$ adaptor from a $5.0 \mathrm{~mm}$ endotracheal tube was used to connect the nasal prongs to the CGO and the $Y$-piece. From the Y-piece, flow was measured with the adjustable pressure release (APL) valve completely closed, completely open and at two partiallyopen settings with circuit pressure equilibrated to $10 \mathrm{~cm}$ $\mathrm{H}_{2} \mathrm{O}$ and $20 \mathrm{~cm} \mathrm{H}_{2} \mathrm{O}$.

Three different anaesthetic machines were studied: (1) Ohmeda Excel 210, (2) Penlon AM 1000, and (3) Ohio Heidbrinck Kinet-o-meter. Each machine was checked with the disposable circle system and rebreathing bag used in the study to verify that there were no leaks greater than $300 \mathrm{ml} \cdot \mathrm{min}^{-1}$ present. In each configuration, oxygen flow at flowmeter settings of three, five and eight $\mathrm{L} \cdot \mathrm{min}^{-1}$ was measured twice and the mean taken (except the Ohio machine, which had a maximum flow rate of six $\mathrm{L} \cdot \mathrm{min}^{-1}$ ). Although flow rates through nasal prongs should not exceed $6 \mathrm{~L} \cdot \mathrm{min}^{-1},{ }^{1}$ measurements were made at $8 \mathrm{~L} \cdot \mathrm{min}^{-1}$ since some of our colleagues administer oxygen via nasal prongs at this rate with the APL valve open to decrease distension of the anaesthetic reservoir bag.

The accuracy of the flows in all of the configurations was compared with each other, using the method of Bland and Altman. ${ }^{6}$ Accuracy was defined as agreement with the flowmeter setting. The difference between each configuration's flow rate and the set flow rate was determined and the mean of the difference calculated. The mean differences were compared using the KurskalWallis test, with Dunn's procedure post hoc for multiple comparisons; $P<0.05$ was considered statistically significant.

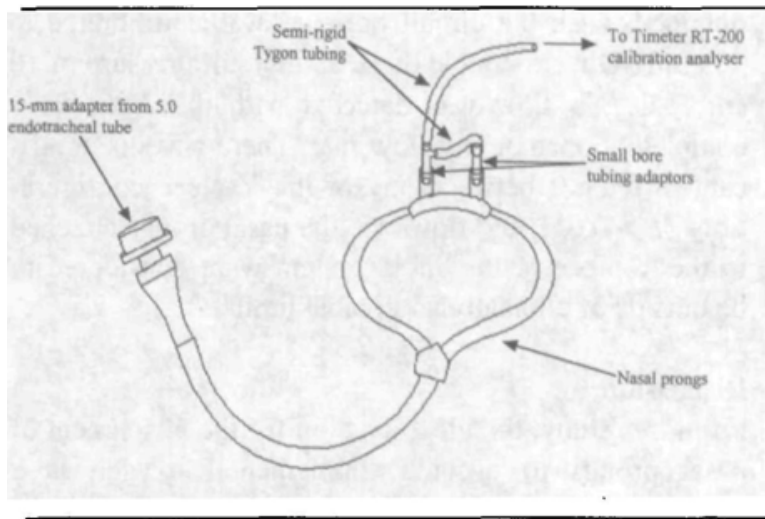

FIGURE 1 Nasal prongs test apparatus.

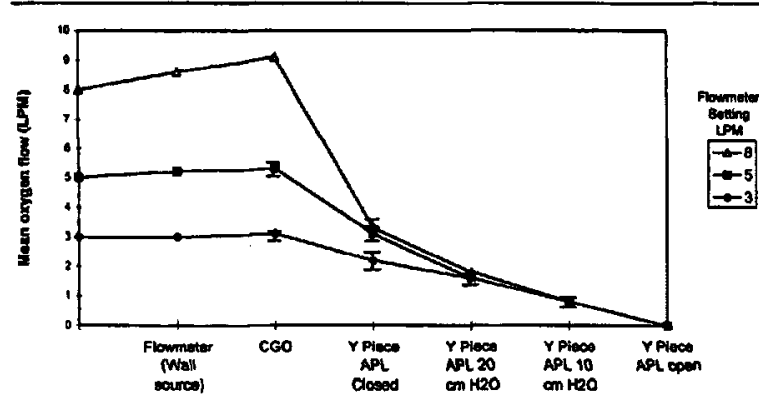

FIGURE 2 Oxygen flow via nasal prongs at different attachments to the anaesthetic machine (mean $\pm \mathrm{SD}$ ).

\section{Results}

The mean oxygen flow from the Ohmeda, Penlon and Ohio machines at each rate and configuration was calculated (Figure 2). The standard deviation for 9 of the 18 points was 0 , and ranged from 0 to $0.42 \mathrm{~L} \cdot \mathrm{min}^{-1}$ for the rest of the data.

The accuracy of the various configurations differed $(P<0.0001)$. The results indicated that flows measured when the nasal prongs were connected to an independent oxygen flowmeter were most accurate (mean difference $0.2 \pm 0.2 \mathrm{~L} \cdot \mathrm{min}^{-1}$ ) followed by connection to the CGO $\left(0.4 \pm 0.4 \mathrm{~L} \cdot \mathrm{min}^{-1}\right)$. The difference between the accuracy of the flowmeter compared with CGO was not significant $(P=0.104)$, and both were considered to be within clinically acceptable limits. With the nasal prongs connected to the Y-piece of the circle system, measured flows were lower than the set rates, especially at high flows (mean difference $-2.1 \pm 1.6,-3.3 \pm 2$, and $-4.2 \pm 2$ when the APL valve was closed, open to 20 and to $10 \mathrm{~cm} \mathrm{H}_{2} \mathrm{O}$ respectively). The delivered flow with the APL valve open was independent of the set flow rate and dependent on the system pressure. Flows 
obtained when the circuit pressure was equilibrated to $20 \mathrm{~cm} \mathrm{H}_{2} \mathrm{O}$ were double those at a circuit pressure of 10 $\mathrm{cm} \mathrm{H}_{2} \mathrm{O}$. No flow was detected with the APL valve completely open at any flow rate. There was no significant difference between any of the $\mathrm{Y}$-piece configurations $(P>0.05)$, and flows via the nasal prongs attached to the Y-piece of the circle system were considered to be outside of clinically acceptable limits.

\section{Discussion}

From this study, the ideal location for the attachment of nasal prongs to provide supplemental oxygen is a flowmeter that is distinct from the anaesthetic machine, either a wall flowmeter or a flowmeter on an E-tank oxygen cylinder. A distinct flowmeter allows direct attachment of nasal prongs, gives accurate delivered flows, and keeps the anaesthetic machine and circuit intact in case of need for urgent use. When an accessory oxygen flowmeter is unavailable or inconvenient (a full E-tank contains only 659 L oxygen) ${ }^{7}$, the next best place of attachment for nasal prongs is the CGO. The flow rates obtained are more accurate than those from any other connections to the anaesthetic circuit, but a $15-\mathrm{mm}$ adaptor from an endotracheal tube must be employed and the circuit disconnected. In case of the need for assisted ventilation, some anaesthetists are reluctant to add another step towards emergency airway management and are fearful that they may neglect to reconnect the circuit to the CGO.

With the nasal prongs connected to the Y-piece of the circle system and the APL valve closed, the pressure drop from the CGO to the end of the nasal prongs is dampened by the reservoir bag. There were no leaks present in the reservoir bag, carbon dioxide absorber, or anaesthetic machine to account for the discrepant flow measurements. Some anaesthetists open the APL valve when nasal prongs are connected to the $Y$-piece to prevent the reservoir bag from over-distending and decreasing its elasticity. Opening the APL valve decreases the pressure differential as the scavenging system offers a path of lesser resistance, allowing the flow to be diverted. When the APL valve was manipulated to maintain a constant pressure, flow was independent of the dialed flow rate but dependent on the pressure maintained in the circuit. From Poiseuille, laminar flow is directly proportional to the pressure difference between the two ends of the tube when all other variables are equal. Of note, the flow rates obtained with a circuit pressure of $20 \mathrm{~cm} \mathrm{H} \mathrm{H}_{2} \mathrm{O}$ were approximately double those at $10 \mathrm{~cm}$ $\mathrm{H}_{2} \mathrm{O}$. No flow occurred when the APL valve was open since the pressure differential was zero.

As a guideline, $\mathrm{FIO}_{2}$ increases approximately $4 \%$ for each $\mathrm{L} \cdot \mathrm{min}^{-1}$ of oxygen delivered via nasal prongs, starting at $24 \%$ for $1 \mathrm{~L} \cdot \mathrm{min}^{-1}$, reaching a maximum of $44 \%$ at $6 \mathrm{~L} \cdot \mathrm{min}^{-1} .1$ There is variability of $\mathrm{FIO}_{2}$ within and between patients breathing via nasal cannulas, and the estimated mean $\mathrm{FIO}_{2}$ varied from $23.7 \%$ to $34.9 \%$ in seven patients breathing via nasal cannulas at 2 $\mathrm{L} \cdot \mathrm{min}^{-1}{ }^{2}$ Flows greater than $6 \mathrm{~L} \cdot \mathrm{min}^{-1}$ do not increase the $\mathrm{FlO}_{2}$ since the anatomical reservoir of the nose, nasopharynx and oropharynx (volume approximately 50 $\mathrm{ml}$ ) is already filled. ${ }^{1}$ Higher gas flows dry and irritate the mucosal surface of the airway and can result in epistaxis, earache, bronchospasm, and substernal chest pain. ${ }^{8}$ The nasal passages must be patent to receive benefit from supplemental oxygen via nasal cannulae.' A higher proportion of mouth breathing can lower the alveolar concentration of oxygen, ${ }^{3}$ although another study did not show any change in oxygen saturation related to the breathing route. ${ }^{4}$ The effective $\mathrm{FlO}_{2}$ varies inversely with tidal volume, respiratory rate ${ }^{1}$ and peak inspiratory flow. ${ }^{5}$

Intravenous sedation is often employed in conjunction with local, regional or neuraxial anaesthesia. Conscious sedation is defined as a technique where the patient is adequately sedated, amnestic, relaxed, and relieved of pain while maintaining airway patency and the ability to communicate. ${ }^{9}$ However, transient but considerable hypoxaemia has been noted in patients undergoing conscious sedation. ${ }^{9}$ It is desirable to provide supplemental oxygen to all patients who receive conscious sedation in the operating room. ${ }^{9}$ Since nasal prongs deliver variable concentrations of oxygen, depending on attachment, flow rate, degree of mouth breathing, tidal volume, respiratory rate and peak inspiratory flow, adequacy of oxygenation should ultimately be ensured by continuous monitoring of oxygen saturation with a pulse oximeter.

\section{Conclusions}

Oxygen flow via nasal prongs was most accurate when the prongs were connected to a distinct flowmeter or the CGO of an anaesthetic machine via a $15 \mathrm{~mm}$ connector; they were more accurate than any attachment via the Y-piece of the circle system. To deliver supplemental oxygen to patients undergoing conscious sedation in the operating room when there are no distinct flowmeters, nasal prongs should be attached either to the CGO of the anaesthetic machine or to a flowmeter on a portable E-tank oxygen cylinder. Connecting nasal prongs to the $Y$-piece of a circle system should be avoided since oxygen delivery is considerably less than dialed, especially when the APL valve is open.

\section{Acknowledgments}

Assistance from Dr. C. Brian Warriner in reviewing the 
manuscript, Pamela M. Merrick in performing statistical analysis and Adam Wilkins in preparing the figures is gratefully acknowledged.

\section{References}

1 Shapiro BA, Kacmarek RM, Cane RD, Peruzzi WT, Hauptman D. Clinical Application of Respiratory Care, 4th ed. St. Louis: Mosby Year Book, 1991.

2 Bazuaye EA, Sione TN, Corris PA, Gibson GJ. Variability of inspired oxygen concentration with nasal cannulas. Thorax 1992; 47: 609-11.

3 Bethune DW. Collis JM. An evaluation of oxygen therapy equipment. Experimental study of various devices on the human subject. Thorax 1967; 22: 221-5.

4 Gould GA, Forsyth IS, Flenley DC. Comparison of two oxygen conserving nasal prong systems and the effects of nose and mouth breathing. Thorax 1986; 41 : 808-9.

5 Ooi R, Joshi P, Soni $N$. An evaluation of oxygen delivery using nasal prongs. Anaesthesia 1992; 47: 591-3.

6 Bland JM, Altman DG. Statistical methods for assessing agreement between two methods of clinical measurement. Lancet 1986; I: 307-10.

7 Dorsch JA, Dorsch SE. Understanding Anesthesia Equipment, 2nd ed. Baltimore: Williams \& Wilkins, 1984.

$8 O^{\circ}$ Connor BS, Vender JS. Oxygen therapy. In: Vende JS (Ed.). Critical Care Clinics. Respiratory Procedures and Monitoring. Philadelphia: W.B. Saunders Co., 1995;11: 67-78.

9 Wetchler BV. Outpatient anesthesia. In: Barash PG, Cullen BF, Stoelting RK (Eds.). Clinical Anesthesia, 2nd ed. Philadelphia: J.B.Lippinicott Company, 1992: 1389-416. 